\title{
Una escritura muy bella. La politicidad de la metáfora*
}

\author{
Silvana Mercedes Casali ${ }^{* \star}$ \\ Recibido: 2019-06-24 • Enviado a pares: 2019-07-13 \\ Aprobado por pares: 2019-08-28 • Aceptado: 2019-09-20 \\ https://doi.org/10.22395/angr.v18n36a6
}

\begin{abstract}
Resumen
El presente artículo toma como estudio de caso la novela Una muchacha muy bella (2013) del escritor argentino Julián López y se enfoca en el análisis de sus metáforas, especialmente aquellas que, mediante un tratamiento sumamente poético del lenguaje, evocan el terrorismo estatal, contexto social dentro del cual transcurre la narración. En tanto nos encontramos ante figuras retóricas que funcionan al poner en relación dos palabras por semejanza, su uso no solo revela las decisiones escriturarias y las preferencias estéticas del autor, sino también la necesidad de su empleo para dar cuenta del carácter indecible e inefable de lo que se intenta narrar, y cuya potencialidad política la metáfora contiene y sugiere. Con el objetivo general de poner a dialogar la producción literaria de una época con el contexto social y político en que surge, en primer lugar, inscribimos la novela en el universo de las narrativas de la segunda generación de la posdictadura que emergieron durante el período kirchnerista. Luego nos centramos en las metáforas enunciadas en la primera parte de la novela por la voz del narrador niño, específicamente aquellas que remiten al clima amenazante propio del momento represivo. Finalmente, señalamos la tensión que esta novela implica en la serie de los relatos pertenecientes al "familismo" y proponemos así pensar la práctica escrituraria en su dimensión política, es decir, en su capacidad para habilitar otras voces y otros modos del decir de la memoria colectiva.
\end{abstract}

Palabras clave: literatura; literatura contemporánea; novela; memoria colectiva; Argentina; dictadura; escritura; política.

Artículo de investigación asociado a los estudios de Doctorado en Comunicación adelantados por su autora en la Universidad de Buenos Aires, Argentina. Se origina como ponencia presentada a las iv Jornadas de Estudios de América Latina y El Caribe, América Latina: entre el asedio neoliberal y los desafíos emancipatorios (Iealc), Facultad de Ciencias Sociales, Universidad de Buenos Aires, Buenos Aires, Argentina, llevada a cabo del 15 al 17 de noviembre del 2018.

* Doctoranda en Comunicación, Universidad Nacional de La Plata, Argentina. Profesora del laboratorio creativo de escritura, Universidad Nacional de La Plata, Argentina. Correo electrónico: silvana.m.casali@gmail.com. Orcid: https://orcid. org/0000-0001-7882-1501 


\title{
A Very Beautiful Writing. The Politicity of Metaphor
}

\begin{abstract}
This article addresses a case study of the novel Una muchacha muy bella (2013) by Argentine writer Julián López, it focuses on the analysis of its metaphors, especially those that, through an extremely poetic treatment of language, evoke state terrorism, social context within which the narration takes place. While we are faced with rhetorical figures that work by relating two words by similarity, their use reveals not only the author's writing decisions and aesthetic preferences, but also the need for their use to account for the unspeakable and ineffable nature of what they narrate; their political potentiality is contained and suggested in metaphor. With the general objective of putting the literary production of an era to dialogue with the social and political context in which it arises, in the first place, we enroll the novel in the universe of the narratives of the second generation of post-dictatorship that emerged during the Kirchnerist period. Then we focus on the metaphors that are enunciated in the first part of the novel by the voice of the child narrator, specifically those that refer to the threatening climate of the repressive moment. Finally, we point out the tension that this novel implies in the series of stories pertaining to "familism", proposing to think about the writing practice in its political dimension, that is, in its ability to enable other voices and other ways of saying collective memory.
\end{abstract}

Keywords: literature; contemporary literature; novel; colective memory; Argentina; dictatorship; writing; politics.

\section{Uma escrita muito bela. A politicidade da metáfora}

\section{Resumo}

Este artigo toma como estudo de caso o romance Una muchacha muy bella (2013), do escritor argentino Julián López, e está focado na análise de suas metáforas, especialmente as que, por meio de um tratamento sumamente poético da linguagem, evocam o terrorismo estatal, contexto social no qual a narração transcorre. Enquanto nos encontramos ante figuras retóricas que funcionam ao colocar em relação duas palavras por semelhança, seu uso não somente revela as decisões de escrita e as preferências estéticas do autor, mas também a necessidade de seu emprego para evidenciar o caráter indizível e inefável do qual se tenta narrar e cuja potencialidade política, a metáfora, contém e sugere. Com o objetivo geral de dialogar sobre a produção literária de uma época com contexto social e político em que surge, em primeiro lugar, inscrevemos o romance no universo das narrativas da segunda geração da pós-ditadura que emergiram durante o período kirchnerista. Logo, focamo-nos nas metáforas enunciadas na primeira parte do romance pela voz do narrador criança, em específico, aquelas que remetem ao clima ameaçador próprio do momento repressor. Por último, sinalizamos a tensão que esse romance implica na série de relatos pertencentes ao "familismo" e propomos, assim, pensar a prática da escrita em sua dimensão política, isto é, em sua capacidade para habilitar outras vozes e outros modos de dizer da memória coletiva.

Palabras chave: literatura; literatura contemporânea; romance; memória coletiva; Argentina; ditadura; escrita; política. 


\section{Introducción}

En Argentina, el análisis de la relación entre literatura y política cuenta ya con un largo recorrido. Podemos ubicar su momento inaugural en La historia de la literatura de Ricardo Rojas, que en su periodización parece advertir que "los ciclos de la evolución literaria no siempre son paralelos y sincrónicos a los ciclos de evolución política" (Prieto, 2006, p. 186), y luego en obras posteriores como Literatura argentina y política del contornista David Viñas (2017) o la Historia crítica de la literatura argentina bajo dirección de Noé Jitrik (2002). Más cercanos en el tiempo, estudios como los de Martín Prieto (2006) o Carlos Gamerro (2015) abonan los debates que tienden puentes entre esa pareja que comparte el trabajo con lo simbólico, principalmente a partir de palabras, pero también de gestos.

Ricardo Piglia señaló que existen autores que logran "ficcionalizar la política y desplazarla del centro del relato para hacerla funcionar como su trama secreta" y que a partir de allí "todo el texto puede ser visto como una metáfora" (Piglia, 1993, p. 91). Esto nos permite intuir que la dimensión política de una ficción escrita no "funciona", no cuando explicita sus principios partidarios o sus intencionalidades ideológicas, sino por el contrario, cuando trabaja con el lenguaje de manera tal que lo político se presenta de manera "sutil y connotada" (Drucaroff, 2011). Este tratamiento sobre el lenguaje que permite el registro discursivo ficcional es el que logra narrar experiencias políticas traumáticas. Allí la literatura muestra que "hay acontecimientos que son muy difíciles, casi imposibles, de trasmitir, y suponen una relación nueva con los límites del lenguaje" (Piglia, 2001). Es en esta línea de discusión que enmarcamos Una muchacha muy bella, la primera novela de Julián López.

Si bien por su fecha de nacimiento el autor ${ }^{2}$ podría pertenecer a lo que Drucaroff (2011) llamó "primera generación de postdictadura", hay razones para pensarlo dentro de la "segunda generación". Por un lado, su escritura se aleja de la mirada heroica de la generación de militancia y se inscribe dentro de las nuevas narrativas, sobre las cuales una extensa bibliografía ha trabajado los rasgos temáticos y formales compartidos, como el hecho de tomar la palabra, acudir a objetos del pasado como fotografías o juguetes, el uso de un lenguaje políticamente incorrecto, el humor, el cuestionamiento

Piglia hacía referencia a Juan José Saer, Manuel Puig, Rodolfo Walsh y Germán Rozenmacher, quienes han trabajado al peronismo desde una mirada elíptica en sus ficciones. Consideramos que esta idea es legítima para nuestro corpus, pues nuestra hipótesis plantea un diálogo subterráneo entre los discursos oficializados sobre memoria colectiva durante el periodo kirchnerista y el tratamiento crítico de las ficciones.

2 Nació en Buenos Aires en 1965 y vivió parte de su infancia bajo dictadura. Su madre murió de muerte civil cuando él era pequeño. Es poeta, razón que explica el tratamiento estético de su escritura en prosa, donde las descripciones detenidas -acerca de la cara de la madre, la forma de su pelo, el color de su piel- generan una sensación de belleza: "para mí todo lo que hago tiene como objeto la poesía" (Llaneza y Griffín, 2015, p. 73). La búsqueda de la belleza, gesto asociado arquetípicamente al poeta, se manifiesta incluso en escenas como el miedo a la desaparición de la madre o la consciencia de la peligrosidad del mundo. En 2004 publicó el libro de poemas Bienamado y desde 2006 coordina el ciclo de lecturas "Carne Argentina". En 2018 Random House publicó su segunda novela, La ilusión de los mamíferos. 
a la lucha armada de los padres y el descreimiento frente a la militancia (Merbilhaá, 1997; Badagnani, 2013; Drucaroff, 2011; Kohan, 2014; Logie, 2015; Daona, 2015; Mandolessi, Blejmar y Pérez, 2018; Basile, 2019). A esto se debe sumar el uso de una voz autoficticia, inscripto en el contexto más amplio del giro subjetivo (Sarlo, 2005) que permite construir un mundo íntimo, familiar y privado, alejado de las exigencias del género testimonial. Lo narrado podría haberle sucedido al autor, y por lo tanto la novela podría ser pensada como una autoficción (Alberca, 2007), o al menos como puesta en crisis de lo que Leujeune (1991) llamó "pacto autobiográfico", en el que la identidad entre autor y narrador coincide, en la que lo que se cuenta efectivamente pasó.

A lo anterior debemos agregar el año de aparición de la novela, que coincide con el período en que se publicó una cantidad significativa de obras de la segunda generación de posdictadura, es decir, luego de la crisis del 200133, acontecimiento que inevitablemente marcó la producción literaria de allí en adelante (Hernaiz, 2006). A diferencia de la supuesta falta de acontecimiento que la crítica especializada ha señalado en la literatura producida por la primera generación de posdictadura durante la década de 1990, en la que hay "personajes dolorosamente vaciados por una Historia que no ha sabido tejer para ellos continuidad y transmisión" (Drucaroff, 2011, p. 123), en las obras posteriores al 2001 "aparece una tendencia a la narrativa de trama fuerte y vertiginosa" (2011, p. 186).

Al inscribir la novela de López en la narrativa de segunda generación persiste el problema, no solo de la autoridad para narrar un tema como el terrorismo estatal, sino también uno más general acerca de la capacidad para escribir sobre lo que no se ha tenido experiencia. Gamerro (2015) retoma la reflexión ensayística que elabora Benjamin (1933) sobre la experiencia y afirma que justamente la motivación para escribir ficción aparece allí donde un acontecimiento no fue vivido. En ese sentido, Una muchacha muy bella activaría lo que el autor denominó "autobiografía en negativo", que consiste en narrar no lo que sucedió, sino lo que podría haber sucedido. Así, Julián López escribe como si su madre hubiese sido una militante desaparecida y en un mismo movimiento salda la pregunta por si es posible escribir sobre un tema sensible en términos sociales y que no le ha sucedido al autor. Es una pregunta por capacidad de narrar una experiencia y también por la discusión más amplia entre historiografía y la ficción. Si bien es sabido que la pretensión de verdad varía según el género discursivo y que en la literatura importa más lo verosímil que la verificación,

[... las narraciones propias de la ficción pueden implicar también reivindicaciones de verdad en un nivel estructural o general, pues aportan discer-

Se conoce como "crisis del 2001" al estallido social, económico y político ocurrido en Argentina tras una década de medidas neoliberales -cuyo inicio varios autores señalan en 1976- y en la que la resistencia social se asocia simbólicamente con las jornadas del 19 y 20 de diciembre, tras la declaración del estado de sitio por parte del entonces presidente Fernando de La Rúa y la represión policial que dejó como saldo 39 muertos. 
nimiento acerca de fenómenos como la esclavitud y el Holocausto, ofrecen una lectura de un proceso o un período, o generan una "sensibilidad" ante la experiencia y la emoción que sería muy difícil de conseguir a través de métodos documentales estrictos. (LaCapra, 2005, p. 38)

Esta dimensión resulta clave por dos motivos. En primer lugar, implica pensar que lo ocurrido en los setenta atravesó al autor de forma generacional, constituyéndose en "la materia misma de la que está hecho" (Gamerro, 2015), lo que habla de la importancia de la generación como, precisamente, generadora ${ }^{4}$ de imaginarios precisos y compartidos en una época particular. Por otro lado, el poderse inscribir en el campo de las narrativas de la segunda generación de postdictadura -pero más específicamente en la narrativa de hijos de militantes desaparecidos sin serlo su autor-, habla de un clima de la época que habilita la emergencia y circulación de relatos que difícilmente hubiesen sido celebrados en un ambiente adverso a las causas de derechos humanos, como sucedió durante la vigencia de las llamadas "leyes de impunidad" que conformaban el imaginario dominante de la década de 1990.

La mediación entre la autobiografía en negativo del autor y el surgimiento de Una muchacha muy bella es la escritura, práctica que permite pensar en condicional: "¿qué hubiera pasado si...?". Si a esas condiciones que habilitan la emergencia de una novela cuyo autor puede "jugar" a ponerse en el lugar de un hijo de madre desaparecida sumamos las prerrogativas que brinda el género discursivo ficcional, el resultado puede ser una novela que dialoga con su tiempo, puesto que surgen nuevas formas de narrar y nuevos autores, alejándonos un paso más de la lógica del "familismo" y su construcción antagónica sobre los "afectados" y los "ciudadanos" (Jelin, 2007), aun teniendo en cuenta que el narrador es un hijo.

\section{En contexto}

En una sociedad que condiciona lo pensable y lo decible, las regularidades "están dotadas de inteligibilidad y aceptabilidad" (Angenot, 2010, p. 14) en un estado social específico. Una muchacha muy bella se escribió y publicó durante el período kirchnerista. Varios autores han señalado como características representativas del período: la vuelta de la juventud a la política (Natanson, 2012), la conformación de una nueva generación de militancia y la recuperación de una mística militante (Natalucci, 2014), y la discusión sobre los setenta. Para Drucaroff (2011), luego del desencanto de la juventud hacia la política en la década de 1990, "los gobiernos kirchneristas abrieron

${ }_{4} \quad$ En otro artículo (Adamini y Casali, 2018) hemos realizado un estudio de caso de Los topos (2008) de Félix Bruzzone. En este nos centramos en lo generacional como una dimensión fundamental que juega más allá de las condiciones favorables -en términos materiales y simbólicos- de las políticas de memoria, verdad y justicia de la década kirchnerista. Y es que buena parte de la narrativa de hijos contienen trayectorias autorales que bien pueden ser pensadas como continuación de la generación setentista. Por caso, la lucha de los hijos contra el neoliberalismo se podría abordar como reanudación de la lucha de los padres contra el imperialismo. 
a los jóvenes la posibilidad de que sí haya algo que mirar y escuchar", algo "que convoque a la pasión" (2011, p. 317). Precisamente, es en la reivindicación de la militancia setentista -trazando un antagonismo frente al terrorismo estatal y al neoliberalismo menemista- que el kirchnerismo construye su identidad (Martínez, 2013). Al respecto, señalan Loreti y Lozano (2017):

Sin dejar de ver sus matices y claroscuros, es posible señalar que el proceso colectivo de construcción de memoria, verdad y justicia encontró su punto culminante en nuestro país a lo largo de los últimos doce años, lo cual se tradujo no sólo [sic] en los juicios que dieron lugar a sanciones penales efectivas para muchos de los responsables, sino también en acciones de parte del Estado en materia de educación, reparación y adopción de medidas que garanticen la no repetición. En simultáneo, y también con un protagonismo central de los organismos de derechos humanos, se avanzó en la generación de mecanismos de acceso a la información y fortalecimiento del derecho a la verdad. La identificación de nietos apropiados, la ampliación de las investigaciones sobre complicidad económica con el terrorismo de Estado y la persecución penal a los responsables civiles del genocidio son algunos de los legados de esta etapa que deberán profundizarse en el futuro inmediato. (Loreti y Lozano, 2017, pp. 294-295)

Esta memoria militante setentista fue señalada tempranamente en la retórica presidencial del ex presidente Néstor Kirchner:

Una característica distintiva del discurso kirchnerista con respecto a otros discursos políticos argentinos contemporáneos es que reivindica, recupera y a la vez reelabora, de manera explícita y articulada, una memoria nunca antes evocada por ningún discurso presidencial, que llamamos "memoria militante setentista", y que remite, a grandes rasgos, a la matriz discursiva, representacional e ideológica de los jóvenes activistas políticos de la década del setenta incluidos en la denominada Nueva Izquierda. (Montero, 2012, p. 283)

Entonces, mediante la implementación de políticas públicas de memoria, verdad y justicia, el kirchnerismo reactualizó el relato de la memoria setentista, que se convirtió en una arista insoslayable al momento de pensar la emergencia de ficciones de segunda generación, casualmente abocadas a escribir sobre el mismo tema, pero con las libertades del género.

\section{Metodología}

Este artículo forma parte del proyecto de realización de una tesis doctoral en Comunicación que aborda las múltiples relaciones entre la literatura y la política. Con el objetivo de analizar los imaginarios que circularon en las ficciones escritas producidas en Argentina durante el período kirchnerista (2003-2015), en principio se construyó un corpus con aquellas obras que la crítica especializada (tanto académica como 
periodística) mentó como significativa y que ha sido publicadas por grandes editoriales durante el tiempo señalado.

Dada la recurrencia temática del topos memoria, en un segundo momento se focalizó en aquellas producciones cuya trama estuviera orientada hacia el pasado setentista, pero cuya narración estuviera centrada o relacionada con el presente, lo cual refuerza las continuidades con ese pasado traumático y la posibilidad de agencia de los sobrevivientes al terrorismo. En ese mismo movimiento, se constató la producción prolífica de escritores jóvenes que habían vivido su infancia durante la dictadura, ingresado a la vida ciudadana durante el menemismo y producido y editado luego de la crisis del 2001, en el transcurso de los gobiernos kirchneristas que, casualmente, llevaron adelante activas políticas de memoria que propiciaron un renovado acercamiento a la discusión sobre los años setenta.

Es debido a estos motivos que se seleccionó un corpus de ocho novelas ${ }^{5}$ escritas y publicadas en el período 2003-2015 por autores que nacieron y/o vivieron su infancia durante la última dictadura militar argentina, que abordan la memoria setentista, han sido promocionados en los principales medios periodísticos gráficos del país y analizados en el campo académico, publicados por editoriales grandes y medianas. Con el fin de reconstruir sus trayectorias, se decidió realizar entrevistas en profundidad a los escritores. Al mismo tiempo, se debe atender al desarrollo editorial luego de la crisis del 2001 para conocer las condiciones de circulación de las producciones. Es en este universo metodológico que se inscribe Una muchacha muy bella de Julián López, obra que aquí se analiza como estudio de caso desde una perspectiva cualitativa.

\section{Desarrollo}

Una muchacha muy bella (2013) está compuesta por dos partes: la primera narra desde la voz de un niño de siete años la amorosa vida cotidiana entre una madre soltera y su hijo, quien no hace más que admirar en silencio a esa mujer e intentar capitalizar los momentos compartidos con ella. La segunda parte comienza luego de que su madre ha desaparecido, el narrador es el mismo, pero ya adulto.

Como vimos, la importancia de las políticas de memoria es crucial. De hecho, el mismo Julián López la nombra al decir que su novela "no podría haber sido escrita sin la política de derechos humanos que empezó Raúl Alfonsín con el Juicio a las Juntas y sin la derogación de las 'Leyes del Perdón' -obediencia debida y punto final- que hace diez años permitió reabrir los juicios y condenar a los responsables de delitos de lesa humanidad" (Friera, 2013).

Actualmente, forman parte del corpus las siguientes obras de ficción escrita: La casa de los conejos de Laura Alcoba (2008), Los topos de Félix Bruzzone (2008), Soy un bravo piloto de la nueva China de Ernesto Semán (2011), Diario de una princesa montonera, 110 \% de verdad (2012) de Mariana Eva Perez, ¿Quién te crees que sos? (2012) de Ángela Urondo Raboy, El espíritu de mis padres sigue subiendo en la lluvia de Patricio Pron (2012) y Las teorías salvajes (2008) de Pola Oloixarac. 
En este contexto favorable a la construcción de una memoria colectiva, Una muchacha muy bella puede ir incluso contra la memoria misma y romper la cristalización en torno a los discursos elaborados desde el poder político, aun cuando estos sean progresistas y reivindiquen la lucha de los organismos de derechos humanos. "El reclamo del narrador es al discurso de la memoria y a cómo se fue construyendo la historia", dice el autor y agrega: "La construcción de la memoria histórica de los años recientes es un discurso que necesita vitalidad" (Friera, 2013).

Frente al riesgo de una posible cristalización de la memoria colectiva, Logie (2016) afirma que el compromiso de la novela radica en la escritura en sí misma, mirada a la que adscribimos:

Con el gesto de la escritura, el protagonista quiere arrancar la memoria de una nueva reapropiación política, una nueva instrumentalización, la de una política de derechos humanos que, por necesaria que sea, le obliga a enjuiciar a su madre, cosa que el narrador se niega a hacer, como se desprende de esta cita: "Me había acostumbrado a pensar que la muchacha bella había sido débil, que había sido fuerte, pero débil para quién, fuerte para quién, cquién pensaba esas cosas en mí, cómo se fueron construyendo esos pensamientos?" (Logie, 2016, p. 151)

Lo que se interpreta del fragmento que toma la autora es el intento por escapar a las interpretaciones que realizan los distintos sectores de la sociedad, no importa quiénes sean. En este sentido, afirma Basile (2019): "Frente a las calificaciones de 'subversivos', 'extremistas' y 'terroristas' que los militares supieron atribuir a sus padres, y de 'víctimas inocentes' dadas por los organismos de derechos humanos, los hijos van a recuperarlos como 'militantes'” (p. 28). La novela va más allá, puesto que tampoco se inscribe en ese rescate reivindicativo de la madre militante. De hecho, más bien señala las imposibilidades de esa militancia ${ }^{6}$.

Además de su retórica militante, el proyecto del gobierno kirchnerista celebró el (re)surgimiento de lo político. Entendemos lo político como la dimensión que atiende al funcionamiento conflictivo de la sociedad, es decir, en su condición ontológica. Lo político es "el movimiento vivo, el magma de voluntades contrapuestas" cuya condición de existencia es el conflicto y cuyo espacio es público, "móvil y ubicuo" (Arditi, 1995, p. 343). De esta manera, para pensar lo político importa tanto lo que está en disputa como la forma que adquiere el enfrentamiento entre los antagonismos.

Si lo político es lo instituyente, lo que irrumpe con la fuerza de lo nuevo sobre la lógica instituida (Alemán, 2016), la política en su forma convencional regula la existencia

6 En una escena el narrador cuenta cómo su madre, frente al televisor, insiste en decir "no pude, no me animé", pues tenía la misión de asaltar un batallón (más adelante nos enteramos que se trataba del asalto al Batallón 601, en Monte Chingolo, pero no se animó a hacerlo. 
del conflicto dentro de los espacios institucionales del Estado. En este sentido, durante el período kirchnerista lo político se institucionalizó y se resignificó desde el poder, no solo el rol de las juventudes y la militancia, sino también el lugar que debe ocupar el conflicto y el poder como constitutivo de lo social (Mouffe, 2007).

Desde aquí es que podemos plantear por qué resulta clave mirar la dimensión de lo político en una ficción escrita como Una muchacha muy bella. En primer lugar, no existen textos apolíticos puesto que "cada texto de ficción es básicamente la expresión de un inconsciente político" (Orloff, 2014, p. 25). Pero además, en esta novela encontramos zonas en las que se presenta lo disruptivo, tanto por lo que se narra como por la forma poética de hacerlo. Frente a una cierta cristalización del discurso de los derechos humanos y de una construcción idealizada en torno a la militancia, pero también frente a una narrativa de hijos que reprocha la opción paterna por la lucha desde un registro por momentos distante o políticamente incorrecto, Julián López construye una militante que se aleja del ideal setentista reivindicado durante y desde el discurso kirchnerista, al tiempo que lo hace con un lenguaje que busca la belleza y que se aleja del humor corrosivo. Como señalamos al comienzo, en un texto de ficción lo político no se debe presentar necesariamente de manera explícita, sino "de manera sutil y connotada" (Drucaroff, 2011, p. 27). En el cuestionamiento a lo instituido anida lo político y por eso en la novela la "juventud maravillosa" no se reivindica ni se rechaza completamente, sino que se humaniza, es decir, se muestra en sus contradicciones, encarnadas en la madre del narrador con sus dificultades para equilibrar maternidad y lucha armada.

Como la literatura construye relatos alternativos frente a, entre otras, las ficciones estatales (Piglia, 2001), por momentos la muchacha muy bella entra en conflicto con la figura de madre que se esperaban según los parámetros de esa época, pero también con la de militante que debe acatar instrucciones precisas. Frente al discurso políticamente correcto que durante el kirchnerismo acompañó la retórica de memoria de la militancia setentista, Una muchacha muy bella irrumpe con otro relato, con otra forma de leer ese pasado que antagoniza con la cristalización del discurso oficial del Estado en el presente.

Además de construir relatos alternativos, la literatura condensa imaginarios sociales, conflictos y tensiones más allá de la voluntad de sus escritores (Drucaroff, 2011). De hecho, tal como lo ha señalado su autor, la palabra "muchacha" acudió a su mente junto con la frase, es decir, sin la intención de encontrar una palabra que remitiera a los años setenta.

La palabra muchacha tiene algo agreste, algo que bordea lo cultural, pero a la vez tiene algo muy vital y a su vez es una palabra de los setenta, con una carga utópica y revolucionaria. Para mí fue muy feliz encontrar esa frase, ahí había algo. (Llaneza y Griffín, 2015, p. 76) 
Esa palabra que atravesará a la manera de un leitmotiv buena parte de la primera narración, habla de la potencialidad de la escritura para contener en sí misma el sentir de una época. "Escribo porque no lo puedo evitar" (Llaneza y Griffín, 2015, p. 71) dice Julián López para contar cómo el deseo por escribir lo asalta y al que no alcanza a percibir conscientemente. "Es una precipitación de algo que en principio no controlo y después le voy encontrando una genealogía interna, una historia" (Llaneza y Griffín, 2015, p. 76).

De esta forma consideramos que lo político se halla en la capacidad performativa que tiene la escritura, puesto que en tanto práctica de sentido posibilita la aparición de temas y formas que pueden no ser conscientes para el artista o la sociedad. Por este motivo Julián López afirma que el acto escriturario es transformador, "porque es esa idea de la plenitud, donde me presento completamente. Eso es como una inyección masiva de información sobre mí mismo. Entonces necesariamente salgo muy agradecido e irradiado de algo. Y está buenísimo que no suceda siempre" (2013 p. 90).

Por el solo motivo de imaginar universos diferentes a los que habitamos y de desafiar la mirada cándida que asegura que es este el mejor de los mundos posibles, la ficción escrita tiene una dimensión política. Su politicidad radica en el desafío al orden social existente, en la capacidad de proyectar la diferencia, de hacer hablar a los otros, de narrar "en negativo", es decir, sobre lo que podría haber sucedido. Además, "alberga en sí misma lo político, puesto que no puede separarse de su contexto histórico, de sus huellas de producción, de una cierta idea de poder, de una concepción del sujeto" (Casali, 2016, p. 48). Esto no implica que su contenido sea panfletario, nos referimos a la presencia "sutil y connotada", en la que las palabras se presentan como agentes capaces de transformar, si no las cosas, la forma de mirar. No necesitamos que el narrador nos cuente qué hacía la madre cuando se ausentaba, a dónde iba o con quiénes se encontraba. Pero sí transmitir que esa madre vive momentos de peligro y por eso mantiene bajas las persianas de su casa y por eso nos va creciendo la sospecha de que en algún momento ya no volverá.

Al haber demostrado el concepto de politicidad y sus formas de aparición en un texto de ficción, es momento de centrarnos en las metáforas.

\section{De metáforas y comparaciones}

Como ya se contextualizó la novela en el campo literario y en el campo social de las memorias, ahora podemos abocarnos a sus metáforas ${ }^{7}$. Como mencionamos, la primera novela de Julián López narra la vida cotidiana de un niño con su madre hasta el día en

\footnotetext{
"Se trata de una figura que pone en relación dos términos por analogía o semejanza. La metáfora puede ser in praesentia (cuando los dos términos están presentes en el texto: 'La luna es un cuerno de plata') o in absentia (cuando está presente solo el término metafórico: 'En la noche oscura brillaba un cuerno de plata')" (Amícola y de Diego, 2008, p. 309).
} 
que ella es secuestrada y, suponemos, desaparecida por un grupo de ocupaciones. Asistimos hasta ese día a una relación de amor y admiración por parte del hijo para con esa "muchacha" de la que no se dice nunca abiertamente que es una militante, pero que ese narrador, pese a ser niño, con sutileza nos hace intuir los peligros que ella corre, los lugares a los que puede ir al ausentarse, la razón de las llamadas telefónicas en la casa de la vecina.

En esa construcción no hay solo una madre, sino también una mujer sensual que por momentos entra en conflicto con su maternidad y encarna la incompatibilidad que por esos años implicaba formar una familia (aquí, además, en que el padre del niño está ausente) y ser parte de la lucha militante. A lo largo de la novela y hasta que desaparezca definitivamente, la madre se ausentará repetidas veces para ir a algún lugar que el hijo desconoce y sobre el cual se abstiene de preguntar. Cuando vuelve de esas escapadas, el hijo nota algo distinto en su madre: "[...] nunca lograba identificar qué era, si la ropa sutilmente desencuadrada, o el pelo más abierto, o todo lo que cambiaba era que su cara se ensanchaba un poco. Tal vez mi madre era más mujer cuando volvía" (López, 2013, p. 31). En ese sugerente "era más mujer cuando volvía" se puede leer lo significativo de ofrecer el cuerpo para una causa colectiva y justa, puesto que deducimos que su madre volvía de reunirse clandestinamente con compañeros de militancia y, a la vez, volvía más mujer porque había sobrevivido. Como si a los ojos del niño, la feminidad materna aumentara al poner en riesgo su vida.

Veamos de qué manera el narrador construye el peligro de la época sin nombrarlo directamente, focalizando en algo más cercano. En el primer caso la madre y el hijo pasean por una plaza, pero en un momento ella debe dejarlo durante un rato al cuidado de una desconocida y sus hijos. Cuando vuelve, el niño piensa:

Mi madre volvía a rescatarme de una escena que no terminaba ni de enamorarme ni de horrorizarme, que tal vez me tenía todo eso y más: completamente fascinado, como los peces brillantes que se quedan inmóviles por el terror a la feroz sepia que los acecha. (López, 2013, p. 31, el destacado es nuestro)

Es recurrente el uso de figuras de animales pequeños e indefensos frente a un otro amenazante al que se le tiene terror, pues se sabe potencialmente asesino, en este caso, "la feroz sepia" que acecha. En otro caso, para referirse a su amigo ocasional en la plaza, dice:

Volví a mirarlo: Santi balanceaba los pies, tenía las manos en puño sobre el banco y levantaba los hombros bien pegados al cuello, otra vez estaba quieto, como la parte honda de una pileta en la que si se cae un chico se ahoga. (López, 2013, p. 33, el destacado es nuestro)

Como recién, lo que acecha es el horror materializado en la comparación que se establece con la muerte de un niño. El efecto se logra por el contraste de narrar la quietud de un niño en la plaza y de golpe construir la imagen de un ahogado. 
Veamos la comparación que utiliza para describir a su madre:

Cada tanto paraba un momento y prendía un 43/70, con el que alternaba la tarea. Pero en ella, en esos momentos, no me parecía un placer sensual. Cada bocanada, tal vez por fumar ese tabaco mezcla de negro y rubio, lejos de afirmarla con el you've come a long way baby, parecía detenerla como a una chica de provincia que mira asustada los carteles de la ruta, acobardada en su huida, a pocos pasos de la salida de su pueblo. (López, 2013, p. 15)

La madre es la mujer en torno a la cual gira la novela, aun tras su desaparición, pues se evidencian las dificultades que enfrenta el narrador adulto para olvidar y continuar con su vida. Razón que lo acercará a la escritura, luego de haberse jurado alejarse de los libros por creer que ellos son responsables de lo sucedido a su madre, lectora de La rama dorada, Cien años de soledad y El varón domado. Con sus siete años, el narrador edípicamente confiesa "me daban ganas de no ser su hijo" (López, 2013, p. 32) y demuestra que lo que más quiere es hacer feliz a su madre, al punto de preguntarse si su actividad favorita no será estar con ella. Como lectores, intuimos que el peligro se avecina y resignificamos ese vínculo hacia el final, con la desaparición materna y más adelante, con las dificultades del narrador con respecto a sus vínculos amorosos.

Para el narrador, la fascinación por su madre se expresa a tal punto que es difícil ponerla en palabras: "Yo adoraba Steinhauser, las tarteletas de frutilla eran un verdadero evento, luminosas como vitreaux de catedral gótica en lo alto de la nave y deliciosas como solo la mejor repostería alemana puede ser". Y a continuación, en la misma página:

Me gustaba sentirme elegante y compartir con mi madre el orgullo de pasar el rato en una salida especial que no iba a poder relatar a mis compañeros de escuela porque lo más encantador, y en ese tiempo no podía desentrañarlo, era lo simbólico. (López, 2013, p. 18)

En esta última oración anida parte de la potencialidad de la literatura: lo simbólico, lo entre-dicho, susurro del lenguaje, lo insinuado: lo que no puede ser nombrado enteramente y solo la ficción permite imaginar. Todo texto literario que se erige como tal cuenta con cierto grado de misterio, una zona que permanece como incógnita y genera deseo. Una muchacha muy bella es una novela de placer y de goce. El placer está en esa infancia feliz, pese a darse en tiempos amenazantes, el goce está en las metáforas que nos ponen "en estado de pérdida" (Barthes, 1978/2014, p. 22) porque nos hablan del miedo.

Elegimos dos escenas en las que encontramos la potencialidad metafórica para hablar de lo que solo puede ser connotado. En la primera el hijo es llevado a la cama por su madre, que lo acuesta y se queda dormida inmediatamente junto a él. Aunque 
tiene sueño, el hijo intenta no dormirse porque disfruta de ver a "esa bella durmiente" a su lado. Llega un momento en que mantenerse despierto le resulta imposible. Entonces, para no dormirse, decide pensar en fieras y así construye una de las escenas más representativas del contexto social, de lo que les aguarda a madre e hijo. Cuando se es niño, pocas cosas son más aterradoras que tener pesadillas. Cuánto más paradójico puede ser si se las invoca voluntariamente, cuánto puede un niño amar a su madre para apelar a la imaginación más sombría solo para estar despierto, junto a ella, un rato más:

Entonces me decidí a pensar en fieras, en enormes tigres acechando, traje lobos aullando desde lejos oliendo el miedo y confiados en el fin de la cacería. Vi a las ovejas obedientes a ese miedo, paralizadas ante la vastedad de la llanura, ante la certeza de no poder sortear esos alambres con que las convencían de su flaqueza. Vi a una de las valientes quedar retenida por las púas del alambre en los rulos de su lana, atascada en posición de huida, quieta, con las demás balándole alrededor para señalarla. Vi a los machos cabríos correr apesadumbrados y lanzarse a un escape bobo. Y vi a las ovejas deambularles a los borregos, intentar esconderlos tras las patas flacas. Llegaron las hienas, unos mamíferos resignados al odio y al desprecio con que fueron alimentados, moviéndose con evidente pereza en la mayor distancia y dando pasos indecisos, merodeando la orden de su olfato pero presas también del surco de su obligación. Vi a las bocas de las ovejas balar sin aire, unos balidos mudos como de ir de frente hacia las fauces, quietas con los ojos abiertos y los oídos llenos de sonidos secos, de carne contra carne, de aliento contra aliento. Vi cómo miraban sin enfocar, con las pupilas dilatadas, al cuadro de la noche entera, vi cómo balaban mudas hasta ser un manchón de tripas en una escena compartida. (López, 2013, p. 52)

¿Quién es la oveja valiente? ¿Quiénes las que señalan a la que ha quedado atrapada? ¿Hay un intento de comprender a las fieras al decir que además de responder a su olfato, son presas de su obligación, como si no tuvieran capacidad de autonomía? La interpretación más fuerte permite que pensemos al narrador como uno de los borregos acechados por los tigres, por los lobos, por las hienas. Frente a la práctica de contar ovejas para dormir, el hijo invoca animales sanguinarios. Esta metáfora tiene la fuerza implícita del contexto argentino: entendemos que esa oveja que queda en el alambrado es su madre, como se devela más avanzada la novela, cuando al colegio vaya a buscarlo la vecina y no su madre, quien ha pasado a integrar la lista de desaparecidos. Los machos que escapan son los padres que se salvan a sí mismos: de hecho, el padre del narrador es una incógnita; solo sabemos que es pelirrojo, como el niño y que abandonó la familia antes de que su hijo naciera. Esos machos cabríos que se lanzan a "un escape bobo", hombres/padres de aquella generación que, ante la necesidad de optar por la familia propia o la familia comunitaria de una revolución posible, optaron por la segunda. El "manchón de tripas en la escena compartida" es una anticipación de lo que ya estaba viviendo la sociedad. 
La siguiente metáfora también se puede interpretar en relación con el contexto dictatorial puesto que simboliza el asombro ante el acostumbramiento de la sociedad frente al terror. A diferencia de la excepcionalidad que implica invocar una pesadilla para permanecer despierto, esta escena constituye la cotidianeidad, el mundo íntimo de madre e hijo. En el desayuno el niño se prepara la leche y cuando ve el cacao depositarse en el fondo, lo asalta el recuerdo de las fosas marinas más hondas del planeta de las que le habló su maestra de geografía y el de su inmediato desconcierto al descubrir que, pese a su existencia amenazadora, las personas continúan con sus vidas:

Me dejaba perplejo saber que la gente convivía con cosas monstruosas que no podría enfrentar, cosas que podrían tragarlas, llevárselas a lo oscuro sin la menor posibilidad de salvarse. Si ese fondo comenzaba a chupar ¿qué cuerpo iba a poder bracear para llegar a la superficie? ¿Y si ese lecho se infiltraba? ¿Si por una grieta mínima comenzaba a gotear el mismísimo océano? ¿Si esa abrumadora masa líquida licuaba los continentes, qué podía pasar con nosotros, íbamos a terminar todos chupados? (López, 2013, p. 80)

Además de la potencialidad de la metáfora para decir algo más de lo que se dice, no podemos dejar de señalar que palabras como chupar y cuerpo agregan otros sentidos si la escena construida se piensa en el contexto político que evoca. Sin dudas que el lector menos informado acerca de lo que sucedió durante el terrorismo estatal argentino puede sentir el desasosiego que siente el niño, pero para el que sabe, el peso simbólico de esas palabras es demoledor, direccionan a una catástrofe compartida socialmente.

Por otro lado, la perplejidad del niño no se debe solamente al hecho de que existan fosas marinas, sino a que las personas tengan conocimiento de ellas y aun así continúen con sus vidas. Aquí podríamos decir que hay una acusación implícita a la sociedad que, bajo dictadura, sospechaba el alcance de los crímenes que se estaban llevando a cabo desde el aparato estatal. Sin embargo, si bien el narrador parece apuntar en esa dirección, el autor ha señalado que su intención no fue tal. El hecho de que una parte de la sociedad conociera o pudiera intuir lo que sucedía no implicaba capacidad de acción para evitarlo: "Las comunidades construyen sus discursos y sus disputas entre todos. Pero a la gente la masacraban. ¿Qué le estás demandando? ¿Que todos sean como el chinito de Tiananmen, 'el rebelde desconocido'? No es posible" (Friera, 2013).

A continuación, el hijo asocia la idea de las fosas marinas con unas vacaciones junto a su madre en Miramar. Ella lo llama para meterse al mar, pero él, por el miedo a la hondura de las fosas, se niega. Se suma también el miedo al perder de vista a su madre en el mar. Es allí cuando repite como un mantra: "que aparezca, que aparezca, que aparezca" (López, 2013, p. 81). Como podemos ver, tampoco es casualidad en el contexto dictatorial que el agua aparezca como símbolo de un peligro inminente, de un 
destino final: los peces brillantes que se deben quedar quietos por temor a la sepia, la pileta honda en la que se puede ahogar su amigo, las fosas marinas y finalmente, el mar.

Tanto la escena en que el niño invoca a las fieras para no caer dormido, como aquella en que toma consciencia de que existen fosas marinas, señalan la potencialidad de la metáfora para construir una época que ha sido traumática, desde un presente que por diversos factores -entre los cuales destaca la reivindicación de lo político y la promoción de políticas públicas de memoria, verdad y justiciaposibilita la emergencia de nuevas formas de narrar el trauma, lejos ya del "familismo" y de dilemas sobre las voces autorizadas para contar la experiencia de una infancia atravesada por el terrorismo.

\section{Discusión y conclusiones}

A lo largo de este artículo hemos analizado el contenido de la novela Una muchacha muy bella teniendo en cuenta su construcción temática en torno a la memoria setentista y la forma poética y metafórica con que la construye. Además, la hemos puesto en relación con datos biográficos y generacionales del autor y de manera más general con su contexto de producción, marcado por políticas públicas de memoria promovidas por y durante el kirchnerismo. De esta manera, hemos visto que se trata de una novela que se puede incluir en el corpus de obras que integran la segunda generación de posdictadura, porque se han ampliado las voces "autorizadas" para narrar junto con los límites de lo decible en nuestra época y porque la ficción escrita permite jugar con imaginarios que desactivan las discusiones en torno al "familismo". Por eso, el autor advierte que se siente parte de lo sucedido, pero no como afectado o ciudadano, sino por pertenencia generacional.

Para señalar la politicidad de la ficción escrita, hemos desarrollado brevemente los rasgos de la dimensión de lo político, que luego nos permitieron pensar la práctica escrituraria en sí misma como expresión de lo disruptivo. Contra la cristalización de los discursos -en este caso, de los derechos humanos-, la escritura se presenta como una práctica política debido a su performatividad y a su dimensión conflictiva, puesto que ilumina conflictos allí donde los sentidos se parecen haber instituido. Y lo hace, como veíamos con Piglia (1993), mediante los desplazamientos del lenguaje. Así, concluimos que el gesto que encarna Una muchacha muy bella es el de ir en contra de los relatos establecidos y proponer una lectura diferente sobre la figura idealizada del militante setentista.

La forma más adecuada de narrar esos nuevos sentidos es, para López, a través de una depuración estilística, un lenguaje poético, la construcción de un punto de vista, una composición, es decir, de una forma resueltamente inactual que se le impuso al autor como la resistencia más apta contra la cristalización de la memoria. (Logie, 2016) 
Una vez atravesada la dimensión política de la obra en cuestión, seleccionamos las escenas más significativas para dar cuenta de la potencialidad que ofrece el lenguaje literario cuando se presenta como metáfora y para afirmar que cuando una obra es leída en correspondencia con el clima de época que busca representar, el análisis gana interpretación. De esta forma, en el contexto en que transcurre la infancia del narrador una palabra como chupar adquiere otra significación.

Además de un equilibro en la tensión entre placer y goce en el sentido barthesiano, en Una muchacha muy bella las metáforas funcionan como umbrales para pensar hechos políticos traumáticos que no necesariamente se asumen a primera vista, pero que iluminan aspectos significativos de la realidad, y que en otro tipo de género de escritura perderían densidad.

En el tratamiento de las escenas más significativas -la pesadilla con las hienas y las fosas marinas-, Una muchacha muy bella restituye a la literatura lo que Drucaroff (2011) denomina su penetración social, su capacidad de dialogar con la realidad. Sus metáforas son políticas porque provocan, desnaturalizan lo cotidiano, porque ven el conflicto allí donde se ha sedimentado el sentido común. Así, en lugar de buscar un sueño agradable, el narrador invoca a las fieras para no dormirse, la chocolatada del desayuno recuerda las fosas profundas con las que convivimos y las que, en un mecanismo de auto-preservación, olvidamos durante el resto del día.

Ricardo Piglia (2001) decía que para un escritor lo social está en el lenguaje y la verdad tiene la estructura de una ficción en la cual es un otro quien cuenta. Hay ficciones escritas que funcionan a manera de umbral a través del cual el lector sale transformado. En la novela en cuestión, López hace un desplazamiento, juega a hacer hablar a ese otro que no fue, narra como un hijo de madre desaparecida. En ese camino, los recuerdos ajenos se vuelven parte de la experiencia propia, pero también de sus lectores, lo cual alimenta la memoria colectiva. Si bien es una obra de ficción, reivindica una verdad pues, como señalamos junto a LaCapra (2005), estas pueden ofrecer lecturas y generar sensibilidades necesarias para la sociedad y difícilmente alcanzables mediante otros registros discursivos.

Acaso el gesto político esté en la escritura que, aunque dirige la mirada hacia el pasado, se decide asentar en el presente. El libro cierra con el narrador adulto que, al escuchar las risas de unas chicas cartoneras que pasan por su ventana, sale de su ensimismamiento. Cuando el lector se ha habituado a ese hombre que solo mira hacia atrás, irrumpe la urgencia del presente. Irrumpe el afuera, la calle, lo real.

\section{Referencias}

Adamini, M. y Casali, S. M. (2018). Memoria setentista en la ficción escrita durante el kirchnerismo. Una explicación generacional para el caso 76 de Félix Bruzzone. Kairos. Revista de Temas Sociales, 22(42). https://dialnet.unirioja.es/descarga/articulo/6981419.pdf 
Alberca, M. (2007). El pacto ambiguo. De la novela autobiográfica a la autoficción. Biblioteca Nueva.

Alemán, J. (2016). Horizontes neoliberales en la subjetividad. Grama.

Amícola, J. y de Diego, J. (2008). La teoría literaria hoy: conceptos, enfoques, debates. Al Margen.

Angenot, M. (2010). El discurso social. Los límites históricos de lo pensable y lo decible. Siglo Veintiuno Editores.

Arditi, B. (1995, enero-marzo). Rastreando lo político. Revista de Estudios Políticos (Nueva Época). (87), 333-351. http://www.cepc.gob.es/publicaciones/revistas/revistaselectronicas?IDR=3EI $\mathrm{DN}=244 \mathrm{EIDA}=16931$

Badagnani, A. (2013). La construcción de las memorias mediante los archivos personales de los hijos de desaparecidos: Ernesto Semán, Mariana Eva Pérez y Ángela Urondo Raboy. VI Jornadas Internacionales de Filología y Lingüística y I de Crítica Genética "Las lenguas del archivo", Facultad de Humanidades y Ciencias de la Educación, La Plata.

Barthes, R. (1978/2014). El placer del texto y Lección inaugural: De la cátedra de Semiología Literaria del Collège de France. Siglo Veintiuno Editores.

Basile, T. (2019). Infancias. La narrativa argentina de Hijos. Eduvim.

Benjamin, W. (1933). Experiencia y pobreza. https://semioticaenlamla.files.wordpress.com/2011/09/ experienciabenj.pdf

Blejmar, J.; Madolessi, S. y Pérez, M. E. (comps.) (2018). El pasado inasequible: desaparecidos, hijos y combatientes en el arte y la literatura del nuevo milenio. Eudeba.

Casali, S. (2016). Ana escribe la novela de Renzo. Trabajo Integrador Final (TIF) de producción literaria (tesis de grado en Comunicación Social). Universidad Nacional de La Plata. Argentina. http://hdl. handle.net/10915/56381

Daona, V. (2015). Las voces de la memoria en la novela argentina contemporánea: Militantes, testigos e hijos/as de desaparecidos/as (2000-2014) (tesis de doctorado). Universidad Nacional de General Sarmiento. Argentina.

Drucaroff, E. (2011). Los prisioneros de la torre. Política, relatos y jóvenes en la postdictadura. Emecé.

Friera, S. (2013, septiembre 23). "La orfandad es una idea muy difícil para la cultura". Página/12. http://www.pagina1 2.com.ar/diario/suplementos/espectaculos/4-29976-2013-09-23.html

Gamerro, C. (2015). Facundo o Martín Fierro. Los libros que inventaron la Argentina. Sudamericana.

Hernaiz, S. (2006). Sobre lo nuevo: a cinco años del 19 y 20 de diciembre. Revista El Interpretador, (29). https://revistaelinterpretador.wordpress.com/2016/12/21/sobre-lo-nuevo-a-cinco-anosdel-19-y-20-de-diciembre/

Jelin, E. (2007). Víctimas, familiares y ciudadanos/as: las luchas por la legitimidad de la palabra. Cadernos Pagu, (29), 37-60. http://dx.doi.org/10.1590/S0104-83332007000200003

Jitrik, N. (2002). Historia crítica de la literatura argentina. Emecé.

Kohan, M. (2014). Pero bailamos. Katatay. Revista Crítica de Literatura Latinoamericana, Ix (1 1-12), 23-27. 
LaCapra, D. (2005). Escribir la historia, escribir el trauma. Nueva Visión.

Llaneza, S., y Griffín, B. (2015). Lacan y los escritores: hablan los escritores. Revista Conclusiones analíticas. Dossier: Lacan y los escritores, 2(2), 68-90.

Leujeune, P. (1991). El pacto autobiográfico. Suplementos Anthropos, 9, 46-61.

Lejeune, P. (1994). El pacto autobiográfico y otros estudios. Megazul-Endymion.

Logie, I. (2015). Más allá del "paradigma de la memoria": la autoficción en la reciente producción posdictatorial argentina. El caso de 76 (Félix Bruzzone). Pasavento. Revista de Estudios Hispánicos III, (1), 75-89. http://hdl.handle.net/10017/23484

Logie, I. (2016, $1^{\circ}$ semestre). Una muchacha muy bella de Julián López, o el gesto reparador de la escritura. Acta literaria, (52), 59-79. http://dx.doi.org/10.4067/S0717-68482016000100004

López, J. (2004). Bienamado. Carne Argentina.

López, J. (2013). Una muchacha muy bella. Eterna Cadencia.

Loreti, D., y Lozano, L. (2017). Derechos humanos: de la amnistía encubierta a un modelo de justicia impartida. En A. Pucciarelli y A. Castellani (comps.), Los años del kirchnerismo. La disputa hegemónica tras la crisis del orden neoliberal (pp.118-133). Siglo Veintiuno editores.

Mandolessi, S., Blejmar, J. y Pérez, M. (2018). El pasado inasequible. Desaparecidos, Hijos y combatientes en el arte y la literatura del nuevo milenio. Eudeba.

Martínez, F. (2013). Aproximación a algunos tópicos del "discurso kirchnerista". En J. Balsa (comp.), Discurso, política y acumulación en el kirchnerismo (pp. 56- 76). Universidad Nacional de Quilmes y Centro Cultural de la Cooperación Floreal Gorini.

Merbilhaá, M. (1997). Andrea Suárez Córica, Atravesando la noche. 79 sueños y testimonio acerca del genocidio. La Plata, Editorial De la Campana, 1996. Orbis Tertius, 2(4). http://sedici.unlp. edu.ar/bitstream/handle/10915/10421/Documento_completo.pdf?sequence=1 EisAllowed=y

Montero, A. (2012). iY al final un día volvimos! Los usos de la memoria en el discurso kirchnerista (20032007). Prometeo Libros.

Mouffe, C. (2007). En torno a lo político. Fondo de Cultura Económica.

Natalucci, A. (2014). La cultura política durante el kirchnerismo: dos hipótesis sobre la politización. Sudamérica: Revista de Ciencias Sociales, (3), 155-171. https://fh.mdp.edu.ar/revistas/index.php/ sudamerica/article/view/1056/1089

Natanson, J. (2012). ¿Por qué los jóvenes están volviendo a la política? Debate.

Orloff, C. (2014). La construcción de lo político en Julio Cortázar. Ediciones Godot.

Piglia, R. (1993). La Argentina en pedazos. Ediciones de la Urraca.

Piglia, R. (2001). Tres propuestas para el próximo milenio (y cinco dificultades). Conferencia dictada el 
27 de noviembre de 2000 en Casa de las Américas. http://www.casa.cult.cu/publicaciones/ revistacasa/222/piglia.htm

Prieto, M. (2006). Breve historia de la literatura argentina. Aguilar, Altea, Taurus, Alfaguara.

Sarlo, B. (2005). Saer, un original. Revista Orbis Tertius, 10(11), 23-27. http://www.memoria.fahce. unlp.edu.ar/art_revistas/pr.253/pr.253.pdf

Viñas, D. (2017). Literatura argentina y política. Santiago Arcos Editor. 